\title{
Equivational Consensus as a Principle Dialogical Communication
}

\author{
Andrey Mishuchkov \\ Institute of Management \\ Orenburg State University \\ Orenburg, Russia \\ E-mail: unitatem@mail.ru
}

\author{
Sergei Nizhnikov \\ Department of the History of Philosophy \\ Peoples' Friendship University of Russia \\ Moscow, Russia \\ E-mail: nizhnikovs@mail.ru
}

\begin{abstract}
The article is devoted to the comprehension of the problem of equivocative consensus as a heuristic value principle of dialogic communication, creating the possibility of a holistic understanding of the sides of dialogue in the context of polar value worlds (traditionalism and modernism). The development of equivocation is considered in the historical and philosophical sense: as a communicative communicative procedure of dialogical understanding, as a function of the semantic appreciation of concepts, as a mechanism of paradoxical meaning creation. A typology of consensus in an equivocative dialog is proposed, connected with the communicative synergy of the concepts of subjects of traditionalism and modernism.
\end{abstract}

Keywords-equivocation; dialogic communication; equivocative consensus; equivocative dialogue; sacral; profane; traditionalism; modernism

\section{INTRODUCTION}

The development of a modern information society has created a complication of communicative flows and hypertrophy of information for a person. The modern person is in a state of information shock and is clearly not ready to meet with artificial intelligence, which is several times greater than its communicative potential [1]. Mutual understanding has become not just a factor of success in this or that sphere of human life, but a condition for its individual survival in the future and the axiom of survival of mankind as a whole.

With the development of information technologies, mankind has divided into traditional and modern, where there are standards of information processing, value filters in communicative interaction. These differences have deep mental and social reasons, they will largely determine in the future the communicative strategy of communication between two parts of humanity. The split of mankind actualizes the strategy of communicative dialogue, one of the potentials of which is an equivocative consensus, an ambiguous mutual understanding. Communicative society of the future, becoming more mature in its development, largely overcomes the conflicting sides of these two types of society (traditional and modern), will expand the potentials of these societies through synergetic interaction-the complexity of the universality and uniqueness of the society in the diversity of the whole. The globalization of markets and cultural spaces has created a phenomenon of multicultural interaction of people on the basis of universal rights and freedoms of the international community, as well as on the basis of their unique cultural identities and traditional values. Such convergence of the semantic flows of traditional and modern concepts in a single polydiscursive communicative space generates the phenomenon of equivocation (two-century, unidirectionality) in cultural contacts, a new cross-cultural dialogic event. Born in this thick of events, equivocal dialogue, ambiguous communication, allows to increase the level of communicative culture of the parties due to the dialectical unity of opposing meanings in communication concepts and create a successful model of communicative intercultural interaction.

The cultural polarity of the world, split by modernization and globalization, becomes, in the conditions of the logic of the duality of dialogue, the possibility of a new synergetic turn of the development of mankind. There is a unique cultural situation of universal communication, when cultural concepts historically included in the civilizational richness of mankind and emerging concepts are equally involved in communicative synergies and express a new horizon of the vital world of human civilization. Certain concepts, both old and new, with little communicability or total repressiveness, create amorphous or conflict zones of communication, which is why they do not fit into the two-vector harmony of universal communication. They continue to be barriers to universal communication, creating a tension energy in the communicated flows of intercultural dialogue. Let us turn to the historical and philosophical analysis of the problem of equivocation as a heuristic key of the universal communication under consideration.

\section{From BOETIA TO THE ABELARD: DUALITY OF THE SUBJECT-SUBSTANCE STATUS}

The term "equivocation" in the modern sense was introduced by Severin Boetzi (480-524), as researcher S.S. Neretina [2]. In his Commentaries on the "Categories" of Aristotle, Boethius established that the term equivocal (ambiguous, equilateral) would be a term in which "one name is common, and the corresponding meaning of the meaning of the substance is different" [3]. First of all, in the 
aspect of the religious picture of the world, it concerns such a fundamental value contradiction as sacral and profane. For example, the term "cognition" has the general meaning of finding new information about the world, additional opposing meanings are the "cognition" of the Creator (the sacred world) and the "cognition" of the creation (the profane world). Love as an emotionally valuable discovery of the created unity (profane) and personal unity in the higher values (sacred). Thus, equivocation is an important means of facilitating dialogue in establishing a common meaning (denotata) on the basis of the intrinsic property of the term used to carry contradictory meanings (sacred and profane connotates) enriching the given meaning.

Boethius, following Aristotle, distinguishes the following types of connection of things and words - equivocal (homonymy), univocal (synonymy), denominative (paronymy); adding to them a diversified (diversivoca) and multivalued (multivoca) [4]. Boethius calls the things that are becoming - equivations, and their names as definitions equivocations. Because of the dual nature of things (properties that have potential properties that acquire things, but which do not yet exist), the names of these things are also paradoxical and combine these properties in their polar definitions. In the spirit of the creationist dogma of creating the world from nothing, the concept of equivocation reveals the meanings of created things from the uncreated words (Logos) of God, generating their ambiguity: the thing (matter) and the name (idea) are inconsistent and inseparable in the consubstantial concept of creation, forming the dual nature of the created of the world. The symbolic and literal interpretation of the Holy Scripture reveals such ambivalence of the word, at the same time, performing the intermediary function of the word between the two worlds (the earthly and the terrestrial). For example, the term "person" can mean both "the image of God" (immortal being) and "intelligent animal" (mortal). The divine revelation speaks sacred language and differs from the ordinary language, which generates all sorts of logical errors when translating the Bible. This is said by Aurelius Augustine (354-430) using the term "ambiguitas" with regard to equivocation as a logical error: "Those who read recklessly, taking one after another, are often deceived by multiple ambiguities and ambiguities" [5]. This tradition of using the term equivocation was fixed in various dictionaries according to logic [6].

The founder of the school of conceptualism, Pierre Abelard (1079 - 1142) used equivocation as a mental procedure for discovering in the name and holding simultaneously two meanings of one concept (for God and for man) in dialogical conversations. As a cognitive principle equivocation shows the duality of the status of existence of things (being and nothing). In his work Yes and No [7], he developed on the basis of equivocation the scholastic, antithetic method of citational opposition of meanings to one concept. Under equivocation it became understood: the ambiguity of the meanings of the name, because the term expresses different aspects of the contradiction; opposite meanings and verbal allegories (trails) due to the figurativeness of the language; double meanings, because of the transfer of terms from one kind of knowledge to another; because of the duality of the subject-substance. According to Abelard: "Only that is called ambiguous, that has a common name and does not express the same meaning of substance" [7].

Thus, equivocative consensus is the most important stimulus of mutual understanding in scholastic dialogues. Formation of an equivocative discourse in the communication of the Middle Ages took place, in the context of a value contradiction between the parties, where ambiguity is a means of overcoming this contradiction.

\section{FROM DELADO TO HEIDEGGER: FROM PARADOX TO SIMULACRA}

Language differentiation in society and speech practices (philosophy, science, culture, etc.) in modern times has further strengthened the importance of equivocation as a cogitative dialogical procedure in terms of the relativity of concepts. In ancient thinking, the ambiguity of the concepts of language was associated with the problem of distinguishing and unifying knowledge (episteme) and opinion (dox) about the subject under discussion. In the Middle Ages in religious thought, equivocation became a feature of metaphysics, which sought the duality of sacred and profane meanings of things.

Since the era of postmodernism in the 20th century, equivocation has become an important feature of secular philosophy due to linguistic differentiation and relativism of concepts. Gilles Deleuze (1925 - 1995) reveals equivocativity (l'equivocité) as a polyphonic paradox of the language and creativity of man. Each concept in the language is a form for a new paradoxical sense formation and, due to the paradoxical nature of human thought activity, a new convergent identity of the new meanings of the concept arises: "a word taken in two senses ensures the similarity or paradoxical identity of these two senses" [9]. Equivocation breaks into the impossible, becoming a semantic whole concept, which is revealed precisely as a paradoxical sense formation, a two-pronged remedy of the concept, which does not have a single frozen form. Equivocative paradox creates a new sense space in a communicative event, modifying the meanings of words, creating non-standard semantic constructions, where the degree of surprise is high, as a result of which new meanings are formed that go beyond the limits of the traditionally expected and predictable. The secular philosophy of language, relying on the relativity of the truth of judgments, actually axioms the ambiguity of linguistic concepts, since all the truths of different linguistic groups are now relative. While in religious thinking ambiguity was generated by the bipolarity of the absolute truths of the divine logos of things and the relativity of the truths of the human concepts of words, in secular thinking, in the communicative situation only the relative truths of the different meanings of the concept occur. In the next step of the language situation, when the artificial intelligence enters the arena of communication, the bipolar derivation of the concept's meanings will be based on the post-primal truths of humanmachine communication, where the place of the divine logos will be taken by the probabilistic-pragmatic meaning of 
concepts with artificial intelligence. Equivocation of meanings (for man and machine) will become the axiom of human cybernetic communication.

If the language differentiation, generated by the technology century, breaks the semantic integrity of the language concepts, then equivocality, as a property of the conceptualization of concepts, restores it. In a meeting of opposing relative truths in the postconventional communication of the present, a synergetic situation arises of the uncertainty of the formation of a new integral meaning of the concept and its linguistic use. As the philosopher Martin Heidegger (1889-1976) notes, equivocation is rooted in the very nature of the autonomy of individuals "'as an abandoned being-friend-in-one in the same world": "Ambiguity concerns not only the disposal and manipulation available for use and use, but it is established already in the understanding of how to be, in the way of throwing and assigning opportunities for presence" [10]. The simulacra of virtual reality (self-referential signs) are common in mass communication-conceptual ambiguities (real-unreal), which overcome the internal conflictuality of meanings (knowledge-opinion) in a dialogical discourse through faith in the plural opinion of other simulacra. The antipode of creative personal equivocation is communicative-mass equivocation as a duality of virtual realities of meanings. Equivocative consensus as the mutual occurrence of meanings in personal communication is opposed in this case to the uncritical consumption of mass concepts in impersonal communication.

\section{TyPology OF CONSENSUS IN EQUIVALENT DiAloG}

Equivocative dialogue is aimed at achieving effective global communication in conditions of value contradiction between the parties. Globalization has strengthened the division of mankind into two worlds: traditionalism and modernism. The modernist project is characterized by the incompleteness, fragmentation and relativity of cultural identities, the dynamics of changes in social institutions and people. The world of traditionalism is historically selfsufficient, complete, based on national cultural identity, on the priority of the past as the algorithm of the future [11]. The subjects of these worlds live in all countries of the world and nowhere form an overwhelming majority.
The schematic image of a communicated subject of traditionalism, includes: reliance on the irrational aspects of concepts (on faith); the irrelevance of the truths of judgments formed in a collective tradition (exclusivism); priority of the spiritual (sacred) over the material (profane); hierarchy of traditional values, which are inherently metaphysical, immutable, absolute; the gravitation towards a collective mentality and a closed type of society; illiberal ideology; subject-subject communication position (the other is the goal); the type of experience is complete, dogmatic.

The image of the subject of modernism is the opposite: rationalism (pragmatism); secularity and relativity of values; Open pluralism and inclusiveness; the priority of the material over the spiritual; priority of rights and freedoms; liberal ideology; subject-object communicative position (the other is a means); type of experience - unfinished, adogmatic.

Equivocative pluralism, based on the consensus of the two sides of the value contradiction, is limited only by the impossibility of religious and moral pluralism, since this threatens cultural identity to the subject of traditionalism [12] The communicative potential of equivocative pluralism remains high enough for the parties to find mutual understanding on key positions. The imperative of such a civilizational consensus is connected with the prospect of the integrity and spiritual survival of the world community on the basis of "intellectual and moral solidarity of mankind" [13].

Equivocative consensus of these subjects concerns all aspects of the communicative event (reflection, evaluation, behavioral act) and includes: recognition of the legitimacy of equivocative concepts and discourses in communication; presumption of equality and dignity of the parties to the dialogue; Dialectic in the knowledge of the ambiguity of the rational and irrational parts of the concept; pluralism of exclusivity and inclusiveness; moral and civil-law consensus; complementarity and synergy of mutual understanding between traditional and post-traditional experience of values; deideologization and demythologization of value concepts of dialogue; disclosure of human potential. The typology of equivocal consensus based on the basic characteristics of the subjects of communication can be presented in "Table I".

TABLE I. The TyPology of CONSENSUS of AN EQUIVOCATIVE DialoG

\begin{tabular}{|l|l|l|l|}
\hline He status of grounds & \multicolumn{1}{|c|}{ The subject of traditionalism } & \multicolumn{1}{|c|}{ The subject of modernism } & \multicolumn{1}{|c|}{ The type of consensus } \\
\hline Gnoseology & Irrational & Rational & Dialectics of Cognition \\
\hline Type of thinking & Exclusivity & Inclusiveness & Pluralism \\
\hline Axiology & $\begin{array}{l}\text { Sacred, the priority of the spiritual over } \\
\text { the material }\end{array}$ & $\begin{array}{l}\text { The profane, the priority of the } \\
\text { material over the spiritual }\end{array}$ & Moral consensus \\
\hline Type of values & Traditional values & System of rights and freedoms & Complementarity \\
\hline Ideology & Non-liberal & Liberal & $\begin{array}{l}\text { Deideologization } \\
\text { demythologization }\end{array}$ \\
\hline Type of relations & Subject-subject & Subject-object & Humanism \\
\hline Mentality & Collective & Individual & Presumption of equality of parties \\
\hline Type of experience & Dogmatic, completed & Adogmatic, unfinished & $\begin{array}{l}\text { Synergy of mutual understanding, } \\
\text { another as part of you }\end{array}$ \\
\hline Type of Society & Closed & Open & Civil-law Consensus \\
\hline
\end{tabular}


When deploying the strategy of equivocative dialogue as a trend in global communication, the possibility of a crosscultural eventuality of mutual understanding between traditional and modern societies is created, and a way out to the synergetic level of civilizational communication.

\section{CONCLUSION}

Therefore, it is possible to draw following conclusions from the above arguments:

- Universal communication of mankind returns to previous forms of dialogical understanding at a new cultural and information level. Equivocative consensus (the ambiguous mutual recognition of meaning in communication) generates a new crosscultural event to overcome the person's value and mental contradictions in the communicated future.

- The prospect of an equivocative consensus in resolving the fundamental contradictions of the human communicative community is potentially high in conditions of multi-elemental, conjugate polar civilizational value systems (traditionalism and modernism).

- The historical and philosophical analysis of the heuristic potential of the communicative procedure of equivocation revealed that: in antiquity it was associated with the overcoming of the contradiction "knowledge-opinion", in the Middle Ages with the "sacred-profane" contradiction, in the present day "real simulacrum", "living-artificial".

- Equivocation in modern communications is considered in the aggregate of essential characteristics: as an internal property of linguistic concepts, expressed in twofold semantic definiteness and incompleteness; As a universal feature of the communicative mind of man; as a function of the semantic conceptualization of concepts; as a mechanism of paradoxical semantic generation and the source of development of language practices; as a heuristic procedure of dialogical thinking.

- The proposed consensus typology in equivocative dialog is connected with two key figures of universal communication - subjects of traditionalism and modernism.

- The equivocal civilization construction of the universal ethics of mankind, based on the consensus and synergy of the projects of traditionalism and modernism in society, will enable us to work out an effective strategy for the safe and humane future of mankind.
[3] Commentary on the "Categories" of Aristotle. / Transl. A.V. Apollonova. // Anthology of medieval thought. T. 1. St. Petersburg, 2001, p. 115

[4] Boethii, In Categorias Aristotelis // MPL. T. 64. Col. 166

[5] S. Aurelii Augustini, Hipponensis episcopi De doctrina Christiana libri quattuor // PL. T. 34. Col. 36.

[6] A.A. Ivin, A. L. Nikiforov, Dictionary of logic - M .: Tumanit, ed Center VLA-DOS, 1997, p. 377.

[7] Blanche B. Boyer, Richard McKeon (eds.). Peter Abailard, Sic et Non A Critical Edition, University of Chicago Press 1977.

[8] Petrus Abaelardus, Glossae super Praedicamenta Aristotelis. Beiträge zur Geschichte der Philosophie des Mittelalters. B. XXI, I. Munster, 1919. p. 117.

[9] J. Deleuze, Difference and repetition. - SPb .: LLP TC Petropolis, 1998 , p. 37.

[10] M. Heidegger, Being and time / Trans. with him. V.V. Bibikhina. Kharkov: Folio, 2003, p. 63.

[11] A. Mishuchkov, S. Nizhniko, Polydiscursive consensus in the context of the tradition and modernity // Proceedings of the 4th International Conference on Education, Language, Art and Intercultural Communication (ICELAIC 2017). Advances in Socia Science, Education and Humanities Research, volume 142. Paris: atlantis-press, 2017, pp. 685 - 689. [Electronic resource]. URL: https://www.atlantis-press.com/proceedings/icelaic-17/ 25886359

[12] A.A. Mishuchkov, Dialogue of Civilizations: Traditional Values in the Context of Globalization (monograph). Orenburg: PKI University LLC, 2017, p. 234.

[13] S.A. Nizhnikov, The problem of spirituality in Western and Eastern culture and philosophy. Monograph. Moscow: INFRA-M, 2012, p 406.

\section{REFERENCES}

[1] Alvin Toffler, Future Shock. New York: Bentam Books, 1970, p. 405.

[2] S.S. Neretina, New philosophical encyclopedia: In 4 vols. M .: Thought. Under the revision of V.S. Styopin. 2001, pp. 417-419. 